\title{
BIM-based cost management of large engineering projects
}

\author{
Lei Lan \\ Guangxi University of Finance and Economics, Nanning, 530003, China
}

Keywords: BIM; engineering project; cost management; BIM

\begin{abstract}
The development of computer technology promotes reform of information technology. Building information model (BUM) is thus applied in cost management of large engineering projects. Thus, some shortcomings of traditional project cost management are solved and improved. One of important topics of "the $12^{\text {th }}$ Five-year plan" science and technology support programs is to research, develop and generalize BIM. BIM leads building industry to enter a higher level. This paper discusses BIM-based cost management of large engineering projects.
\end{abstract}

\section{Overview of BIM}

BIM refers to the model established on the basis of data information in the engineering project. It has important applications in design cost in the early stage of the project and building management in the later period. It belongs to a digital measurement method. BIM is a new computer-aided technology and can implement four-dimensional or five-dimensional simulated construction. It brings convenience for managers to predict, analyze and solve various problems in the initial design stage. The five-dimensional information forms through adding time and cost in BIM thee-dimensional model and reaches the purpose of direct project cost management. BIM can vividly confirm the material mobilization time and resource consumption within schedule scope, reduce storage cost and unnecessary material loss to the largest extent, and carry out dynamic project cost management. So, BIM technology has an important position in cost management of large engineering projects.

\section{Importance of cost management and control of large engineering projects}

(I) Cost management of engineering projects plays a decision role in the whole engineering construction also imposes conclusive impacts on cost control. If the construction unit is seriously short of management, engineering cost may become unreasonable and the accuracy will be low. During changing site certificate of both parties, if the responsibilities of both parties are not specified, and material price is not explicitly changed, a series of problems will occur during project settlement. So, it is required to pay attention to changing the certificate, carry out site management orderly and carefully manage the project so as to control the cost.

(II) Project cost control occupies an important position in the whole engineering construction. In practical construction project, the market positioning of the project is generally measured bidding. But, if relevant bidding system has large defects, cost control will become unreasonable and impact benefits of the whole construction unit and the enterprise. Project cost will increase under the following situations: bid invitation documents have many loopholes in cost control; the work is carried out without base number of the bid; pricing evaluation system is imperfect and lacks enough rationality. Thus, the whole project will be affected. The enterprises which adopt new technology generally have low offer and low production cost, so they have large appreciation space. So, scientific and reasonable project const control is an important index to measure long-term development of an enterprise.

\section{Problems of traditional project cost management}

\section{(I) Cost data acquisition is not timely}

Traditional project cost just serves as a tool to gain cost data and has no time requirement for cost data acquisition. So, the data lack instantaneity, which leads to continuous cost disputes in the 
later period. Cost data are the fundamental precondition of project cost. Real-time cost data have important influences on project cost accuracy. But, due to the limitation of gaining all-round cost information, many data are faked, which leads to large losses to the owner. Cost information in traditional system is also incomplete and cannot provide complete information foundation for decision-making. BIM can control actual cost in real time and achieves accurate comparison of the whole project process through accurate, complete and real-time analysis of cost data so as to make correct decisions.

(II) Cost process is not coherent

Traditional project cost process is as follows: make budget estimate during preliminary design; make budget during construction drawing design; make settlement after the project is over. The cost information involved just serves as a tool of passive accounting. The huge function of cost management on cost control is not reflected. Thus, in final settlement process, a series of compensation events occur due to non-timely cost situations. It is time-consuming, strength-consuming and money-consuming. BIM can closely connect investment with cost, master cost information in each link in real time and gradually form the virtuous circle of first planning and then changing. So, periodic dynamic comparison of planned cost and actual cost is of great significance.

\section{Application of BIM in cost management of large engineering projects}

BIM plays an important promotion role in achieving informatization management of the whole project and also has advantaged superiority for improving project management level and project cost efficiency.

(I) Project cost data sharing

BIM will provide detailed building data, including geometrical information and rule information. Traditional buildings lack information regularity and integrity and fail to form a uniform entirety. Unforeseen circumstances often occur during information data transmission. BIM makes revolutionary progress in allusion to these defects. The same model is used in the whole project period. The sole data export plus the sole model for data change makes data information well protected and improved. Meanwhile, the model replaces paper drawings, which brings convenience for future reference and data sharing. Thus, it owns strong integrated information management function.

Architectural drawings made by traditional two-dimensional designers will go wrong due to some irresistible factors. Limited by two-dimensional space, it is hard for designers to accurately express their design idea. BIM breaks through two-dimensional constraint and plans to make three-dimensional building model. Under real data comparison, designers, cost engineers, material engineers, the owner and engineers can vividly see the project completed. Thus, they can consider possible unstable factors in advance and reach the purpose of control in advance through exchange and sharing among each department.

For example, during construction of Shanghai Center Building, Chinese and American building firms applied BIM during cooperation. Shanghai Center Building is a super high-rise building. Internal invisible pipelines are criss-cross, and the building structure is complicated. If traditional design way is adopted, accidents will inevitably occur and unnecessary economic loss will happen. BIM adopts special model at the beginning of design, which avoids mutual collision situations and makes sure the project is completed as schedule. If traditional design technology is adopted, the loss caused by pipeline collision will reach tens of million. Even shutdown, delay or design scheme change may occur.

(II) Visual management of cost information

Relative to construction project, the larges reform of BIM is design visualization. Visualization technology transforms plane lines to three-dimensional graphs. The design, communication, operation, bid invitation and bidding of the whole project can be completed in the model. BIM-based cost management of large engineering projects links digital information in the cost process in corresponding parts of the model. BIM technology will automatically generate accurate 
cost information of each node or spatial position and can timely refer to and screen the needed information through area selection and virtual wandering. The whole process is finished in four-dimensional model of BIM and has high accuracy. As the construction ends, synchronous cost model will be completed. Such statistics effect of settlement in later period is much more visual than paper drawings. Besides, it is accurate and fast. BIM technology mainly integrates and divides data as data source of each external index in the system so that users can conveniently consult or position so as to achieve information transfer and sharing among each department. The information contents mainly include design drawing, investigation report, equipment information and construction records etc.

(III) Reform traditional cost software

Traditional two-dimensional drawing cost software is limited to the category of measurement and calculation. Regional differences deepen closeness of traditional cost software and single functions. So, it cannot meet modern building demand. Cost software will be integrated with civil engineering measurement and calculation software to research and develop a kind of new measurement software. In this way, different types of users can apply the model in the same software, which brings convenience for saving data in each link. Data integration of different types of specialties means reconstruction of backstage architecture. Original software structure will be thoroughly changed. Besides, it will take a long time to update and improve the software after research and development. The hardware handling capacity of the computer must be matched with the calculated value of new software. Cost software can integrate measurement data of various kinds of cost software. Such mode does not need to change backstage architecture of original software, but just needs to set import and export interfaces on various kinds of cost software. The structure of various kinds of cost software keeps independent. The data are integrated. Dynamic comparison of data forms through network technology. Budget statement, bidding documents and settlement statement are managed uniformly. The payment certificate and construction contract can be set in the project attachment.

In addition, data consultation and review of all projects under construction can be conducted. The histogram and pie chart can be used for visual observation to reach the purpose of cost management and control of all projects. BIM integrates dynamic cost data and building schedule, marks various kinds of information on the basis of visualization to reach links charts, formulas and offer. Any data change will influence relevant data. Abnormal data will be specially shown to remind the manager of multi-dimensional review. This enhances supervision function of project cost, avoids destruction of human factors and greatly improves accuracy of project cost.

\section{Problems in application of BIM in cost management}

In large project construction, thousands of construction materials will be involved. Different users may name different names of the same material. Then, database mark in the later period will become very chaotic. It is thus very difficult to repeat utilization of BIM information database. When users call the database for reference, they cannot find the corresponding name. To make different users have uniform name identification and provide convenience for data consultation, it is necessary to construct BIM information coding classification system. Each component has exclusive IFD proper noun. After refined division, different users in different regions can find corresponding BIM information. Existing classification standard in China cannot be directly used in BIM measurement system. To make BIM become automated as early as possible, it is required to explicitly classify and define each component and achieve standardization.

\section{Methods to implement BIM-based large project cost}

Specialty limitation causes that designers rarely consider actual demand of engineering cost in the later period during designing BIM and will not add cost information. Designers generally take into account of the model form the perspective of design specialty. If BIM is applied in engineering cost link, further optimization is needed. 
Firstly, add cost information in BIM four-dimensional model to reach five0dimensional standard. Such design makes the cost visually displayed in the model. When the design alters, cost information will also change. On the contrary, cost change will influence mode change. But, as engineering project measurement continuously increases, higher requirement is put forward for computer hardware. The coordination force for cost personnel and designers also increase. So, both technology and organization management propose new requirements for personnel.

Secondly, the data in the design stage are exported to cost software and new linkage is established with cost information. Such way is feasible at management level and technology level. But, fundamental architecture of cost software and measurement software is different. Dynamic linkage cannot be set up to observe real-time changes. Design change and cost change need artificial control and additional change.

A large engineering project is divided into multiple stages in actual construction. As project schedule and material price on the market alter, project cost is always in dynamic changes. In traditional cost, design and management are mutually independent. Once the design scheme changes, manual re-estimation is needed. Besides, there is great instability. The project cost after sudden changes cannot be reflected in real time. Therefore, the first scheme has certain advantages. It exports cost differences of different methods through design and management integration mode, visually compares project cost and carries out scientific decision-making.

\section{Examples of BIM-based cost management of large engineering projects}

\section{Conclusions}

In developed countries, BIM use rate has reached 40\%. Many kinds of software derived from BIM gradually enter Chinese market. But, due to data interface and industrial standards, this technology just stays at the design level. To fundamentally achieve informatization management of cost information of large engineering projects, it is required to comply with data interface of Chinese building industry. Currently, BIM-based application software is in continuous exploration, and Chinese BIM standards gradually form. The research, development and generalization of new things suffer difficulties. But, it cannot be denied that the opportunity of applying BIM technology has come with rapid era development. As the largest developing country and the second largest economic entity in the world, it is necessary for China to boost application of BIM technology and promote Chinese building project to further improve!

\section{References:}

[1] He Guanpei, Position, evaluation system and possible application of BIM in building industry [J]. Journal of Information Technology in Civil Engineering and Architecture, 2010(3)

[2] Ma Zhiliang, Application problems of BIM in China and countermeasures [J]. Information of China Construction, 2010(4)

[3] Liu Hongbing, Analysis of project const control in construction stage [J]. China High Technology Enterprises, 2010 (33)

[4] Gan Xia, On all-process control of construction project cost [J]. Management \& Technology of SME, 2009 